\title{
On Fixed and Coincidence Points Under Contractive Mappings in Non-Archimedean Fuzzy Metric Space
}

\author{
Anju Panwar \\ Department of Mathematics, M.D.University,Rohtak(India) \\ E-mail: anjupanwar15@gmail.com, toor.anju@yahoo.com
}

\begin{abstract}
In this paper, we prove some coincidence and fixed point theorems for various contractive mappings in spherically complete nonarchimedean fuzzy metric space. In this space, we also prove the metric locally constancy of a function $\mathrm{f}$. Our results extend various known results in ultra metric space.
\end{abstract}

Keywords: Spherically complete, M.l.c., Non-archimedean, Multivalued metric.

Mathematics Subject Classification: 47H10, 54H25

\section{Introduction}

Non-Archimedean functional analysis has developed rapidly in recent years, as well as its application in mathematical physics. W.H.Schikhof [18] developed the theory of ultra metric calculus. Important contributors in ultra metric/nonarchimedean spaces were Ljiljana Gajic, C.Petalas, Vidalis, Van Roovji, M. Zaharescu, K.P.R. Rao, G. N.V. Kishore and D. Mihet .

The theory of Fuzzy sets was introduced by Zadeh [11].Deng [20], Erceg [12] and Kaleva and Seikkala[14] have introduced the concept of fuzzy metric in different ways. George and Veeramani [1] gave a necessary and sufficient condition for a fuzzy metric space to be complete. Recently, Mihet [2,3] introduced the concept of non-archimedean fuzzy metric space and proved Banach Contraction theorem in this space. 
The notion of metric locally constant function was introduced by M.Vajaitu and A. Zaharescu [13] in order to study certain groups of isometries on a given ultra metric space. Later on L. Gajic[10] obtained some results in spherically complete ultra metric space for generalized contractive mappings using the concept of metric locally constant. In spherically complete ultra metric space the continuity of maps are not necessary to obtained fixed point.

The aim of this paper to obtain some coincidence and fixed point theorems for various contractive mappings in spherically complete non-archimedean fuzzy metric space. Our results extend various known results in ultra metric space.

Definition 1.1 [5]: A binary operation $*:[0,1] \times[0,1] \rightarrow[0,1]$ is a continuous t-norm if it satisfies the following conditions:

(1) * is associative and commutative,

(2) $*$ is continuous,

(3) $\mathrm{a} * 1=$ a for all $\mathrm{a} \in[0,1]$,

(4) $\mathrm{a} * \mathrm{~b} \leq \mathrm{c} * \mathrm{~d}$ whenever $\mathrm{a} \leq \mathrm{c}$ and $\mathrm{b} \leq \mathrm{d}$, for each $\mathrm{a}, \mathrm{b}, \mathrm{c}, \mathrm{d} \in[0,1]$.

Example1.2: Two typical examples of continuous t-norm are $\mathrm{a} * \mathrm{~b}=\mathrm{ab}$ and $\mathrm{a} * \mathrm{~b}$ $=\min (\mathrm{a}, \mathrm{b})$.

Definition 1.3: The 3-tuple $(X, M, *)$ is called a non-Archimedean fuzzy metric space (shortly, N.A. FM-space) if $X$ is an arbitrary set, $*$ is a continuous $t$-norm and $M$ is a fuzzy set in $X^{2} \times[0, \infty)$ satisfying the following conditions:

For all $\mathrm{x}, \mathrm{y}, \mathrm{z} \in \mathrm{X}$ and $\mathrm{s}, \mathrm{t}>0$,

$(\mathrm{FM}-1) \mathrm{M}(\mathrm{x}, \mathrm{y}, 0)=0$,

$(\mathrm{FM}-2) \mathrm{M}(\mathrm{x}, \mathrm{y}, \mathrm{t})=1$, for all $\mathrm{t}>0$ if and only if $\mathrm{x}=\mathrm{y}$,

$(F M-3) M(x, y, t)=M(y, x, t)$,

$(\mathrm{FM}-4) \mathrm{M}(\mathrm{x}, \mathrm{y}, \mathrm{t}) * \mathrm{M}(\mathrm{y}, \mathrm{z}, \mathrm{s}) \leq \mathrm{M}(\mathrm{x}, \mathrm{z}, \max \{\mathrm{t}, \mathrm{s}\})$

Or equivalently $\mathrm{M}(\mathrm{x}, \mathrm{y}, \mathrm{t}) * \mathrm{M}(\mathrm{y}, \mathrm{z}, \mathrm{t}) \leq \mathrm{M}(\mathrm{x}, \mathrm{z}, \mathrm{t})$

$(\mathrm{FM}-5) \mathrm{M}(\mathrm{x}, \mathrm{y},):.[0, \infty) \rightarrow[0,1]$ is left continuous.

(FM-6) $\lim _{n \rightarrow \infty} \mathrm{M}(\mathrm{x}, \mathrm{y}, \mathrm{t})=1$ for all $\mathrm{x}, \mathrm{y} \in \mathrm{X}$ and $\mathrm{t}>0$.

For $\mathrm{t} \in(0, \infty)$, we define the closed ball $\mathrm{B}[\mathrm{x}, \mathrm{r}, \mathrm{t}]$ with centre $\mathrm{x} \in \mathrm{X}$ and radius $r \in(0,1)$ as

$$
B[x, r, t]=\{y \in X, M(x, y, t)>1-r\} .
$$

Definition 1.4: A N.A. FM-space $(X, M$,*) is said to be spherically complete if every shrinking collection of balls in $X$ has a non empty intersection. 


\section{Main Results}

Theorem 2.1: Let $(X, M, *, \diamond)$ be spherically complete non-Archimedean fuzzy metric space. If $T: X \rightarrow X$ is a mapping such that for every $x, y \in X, x \neq y$,

$M(T x, T y, t) \geq \min \{M(x, T x, t), M(x, y, t), M(y, T y, t)\}$

then T has a unique fixed point.

Proof: Let $\mathrm{B}_{\mathrm{a}}=\mathrm{B}(\mathrm{a}, 1-\mathrm{M}(\mathrm{a}, \mathrm{Ta}, \mathrm{t}), \mathrm{t})$ denote the closed spheres centered at a with the radii 1-M(a, Ta, $t)$ and let $A$ be the collection of these spheres for all $a \in X$. The relation $\mathrm{B}_{\mathrm{a}} \leq \mathrm{B}_{\mathrm{b}}$ iff $\mathrm{B}_{\mathrm{b}} \subseteq \mathrm{B}_{\mathrm{a}}$ is a partial order on $\mathrm{A}$.

Now, consider a totally ordered subfamily A1 of A. Since $(X, M, *, \diamond)$ is spherically complete, we have that

$$
\bigcap_{B_{a} \in A_{1}} \mathrm{~B}_{\mathrm{a}}=\mathrm{B} \neq \phi .
$$

Let $\mathrm{b} \in \mathrm{B}$ and $\mathrm{B}_{\mathrm{a}} \in \mathrm{A} 1$. Let $\mathrm{x} \in \mathrm{B}_{\mathrm{b}}$. Then,

$$
M(b, a, t) \geq(1-M(a, T a, t))=M(a, T a, t) .
$$

If $\mathrm{a}=\mathrm{b}$ then $\mathrm{B}_{\mathrm{a}}=\mathrm{B}_{\mathrm{b}}$. Assume that $\mathrm{a} \neq \mathrm{b}$, let $\mathrm{x} \in \mathrm{B}_{\mathrm{b}}$. Then,

$$
\begin{aligned}
\mathrm{M}(\mathrm{x}, \mathrm{b}, \mathrm{t}) & \geq 1-(1-\mathrm{M}(\mathrm{b}, \mathrm{Tb}, \mathrm{t}) \\
& =\mathrm{M}(\mathrm{b}, \mathrm{Tb}, \mathrm{t})
\end{aligned}
$$$$
\geq \min \{\mathrm{M}(\mathrm{b}, \mathrm{a}, \mathrm{t}), \mathrm{M}(\mathrm{a}, \mathrm{Ta}, \mathrm{t}), \mathrm{M}(\mathrm{Ta}, \mathrm{Tb}, \mathrm{t})\}
$$$$
=\min \{\mathrm{M}(\mathrm{a}, \mathrm{Ta}, \mathrm{t}), \mathrm{M}(\mathrm{Ta}, \mathrm{Tb}, \mathrm{t})\} \text {. }
$$

For $\quad M(T a, T b, t)>M(a, T a, t)$ implies that

$$
M(x, b, t) \geq M(a, T a, t) .
$$

In opposite case, $\mathrm{M}(\mathrm{Ta}, \mathrm{Tb}, \mathrm{t}) \leq \mathrm{M}(\mathrm{a}, \mathrm{Ta}, \mathrm{t})$.

$M(x, b, t) \geq M(b, T b, t) \geq M(T a, T b, t)$

$$
\begin{aligned}
& \geq \min \{\mathrm{M}(\mathrm{a}, \mathrm{Ta}, \mathrm{t}), \mathrm{M}(\mathrm{a}, \mathrm{b}, \mathrm{t}), \mathrm{M}(\mathrm{b}, \mathrm{Tb}, \mathrm{t})\} \\
& =\min \{\mathrm{M}(\mathrm{a}, \mathrm{Ta}, \mathrm{t}), \mathrm{M}(\mathrm{b}, \mathrm{Tb}, \mathrm{t})\} .
\end{aligned}
$$

Now, for $M(b, T b, t)>M(a, T a, t)$, we have

$$
M(x, b, t) \leq M(a, T a, t)
$$

The inequality $M(b, T b, t) \leq M(a, T a, t)$ implies that $M(b, T b, t)<M(b, T b, t)$, which is a contradiction. So, we have proved that for $\mathrm{x} \in \mathrm{B}_{\mathrm{b}}$

$M(x, b, t) \geq M(a, T a, t)$.

Now, we have that

$$
M(x, a, t) \geq M(a, T a, t) .
$$


So $\mathrm{x} \in \mathrm{B}_{\mathrm{a}}$ and $\mathrm{B}_{\mathrm{b}} \subseteq \mathrm{B}_{\mathrm{a}}$ for any $\mathrm{B}_{\mathrm{a}} \in \mathrm{A}_{1}$. Thus $\mathrm{B}_{\mathrm{b}}$ is the upper bound for the family A. By Zorn's lemma A has a maximal element, say $B_{z}, z \in X$. We are going to prove that $\mathrm{z}=\mathrm{Tz}$.

Let us suppose the contrary, i.e. that $\mathrm{z} \neq \mathrm{Tz}$. Inequality (2.1) implies that

$$
\mathrm{M}(\mathrm{Tz}, \mathrm{T}(\mathrm{Tz}), \mathrm{t})>\mathrm{M}(\mathrm{z}, \mathrm{Tz}, \mathrm{t})
$$

Now if $\mathrm{y} \in \mathrm{B}_{\mathrm{Tz}}$ then $\mathrm{M}(\mathrm{y}, \mathrm{Tz}, \mathrm{t}) \geq 1-(1-\mathrm{M}(\mathrm{Tz}, \mathrm{T}(\mathrm{Tz}), \mathrm{t}))$

$$
=M(T z, T(T z), t)>M(z, T z, t) \text {. }
$$

So

$$
M(y, z, t) \geq \min \{M(y, T z, t), M(T z, z, t)\}=M(z, T z, t) .
$$

This means that $\mathrm{y} \in \mathrm{Bz}$ and that $\mathrm{B}_{\mathrm{Tz}} \subseteq \mathrm{B}_{\mathrm{z}}$.

On the other hand $\mathrm{z} \notin \mathrm{B}_{\mathrm{Tz}}$ since

$$
\mathrm{M}(\mathrm{z}, \mathrm{Tz}, \mathrm{t})<\mathrm{M}(\mathrm{Tz}, \mathrm{T}(\mathrm{Tz}), \mathrm{t}) .
$$

So $\mathrm{B}_{\mathrm{Tz}} \underset{\neq}{\subset} \mathrm{B}_{\mathrm{z}}$. This is a contradiction with the maximality of $\mathrm{B}_{\mathrm{z}}$. Hence, we have that $\mathrm{z}=\mathrm{Tz}$.

Let $\mathrm{u}$ be a different fixed point. For $\mathrm{u} \neq \mathrm{z}$ we have that

$M(z, u, t)=M(T z, T u, t) \geq \min \{M(T z, z, t), M(z, u, t), M(u, T u, t)\}=M(z, u, t)$

which is a contradiction. The proof is completed.

We denote by $F_{X}$, the set of maps $f: X \rightarrow[0,+\infty)$.

Definition 2.2 A function $f \in F_{X}$ is said to be metric locally constant( shortly, m.l.c.) provided that for any $x \in X$ and any $y$ in the open $B(((x, f(x))$ one has $f(x)=$ $f(y)$.

Proposition 2.3: Let $M$ be an fuzzy ultra metric on $X$.

(1) If $\mathrm{a}, \mathrm{b} \in \mathrm{X}, \lambda>0$, and $\mathrm{b} \in \mathrm{B}(\mathrm{a}, \lambda, \mathrm{t})$ then $\mathrm{B}(\mathrm{a}, \lambda, \mathrm{t})=\mathrm{B}(\mathrm{b}, \lambda, \mathrm{t})$.

(2) If $\mathrm{a}, \mathrm{b} \in \mathrm{X}, 0<\delta \leq \lambda$, then either $\mathrm{B}(\mathrm{a}, \lambda, \mathrm{t})$ I $\mathrm{B}(\mathrm{b}, \lambda, \mathrm{t})=\phi$ or $\mathrm{B}(\mathrm{b}, \lambda, \mathrm{t}) \subseteq \mathrm{B}(\mathrm{a}, \lambda, \mathrm{t})$. Hence, if a ball $\mathrm{B}(\mathrm{a}, \lambda, \mathrm{t})$ contains a ball $\mathrm{B}(\mathrm{b}, \lambda, \mathrm{t})$, then either the balls are the same or $\delta<\lambda$. Every ball is clopen(closed and open) in the topology defined by $\mathrm{M}$.

Theorem 2.4: Let $(X, M, *, \diamond)$ be spherically complete non-Archimedean fuzzy metric space and $T: X \rightarrow X$ contractive mapping. Then there exist subset $B \subseteq X$ such that $T: B \rightarrow B$ and that the function $f(x)=M(x, T x, t), x \in B$, is m.l.c.. 
Proof: Let $B_{a}=B(a, 1-M(a, T a, t), t)$ denote the closed spheres centered at a with the radii $1-\mathrm{M}(\mathrm{a}, \mathrm{Ta}, \mathrm{t})$ and let $\mathrm{A}$ be the collection of these spheres for all $\mathrm{a} \in \mathrm{X}$. The relation

$$
\mathrm{B}_{\mathrm{a}} \leq \mathrm{B}_{\mathrm{b}} \text { iff } \mathrm{B}_{\mathrm{b}} \subseteq \mathrm{B}_{\mathrm{a}}
$$

is a partial order on $\mathrm{A}$.

Let $A_{1}$ be a totally ordered subfamily of A. Since $(X, M, *, \diamond)$ is spherically complete,

$$
\cap_{B_{a} \in A_{1}} \mathrm{~B}_{\mathrm{a}}=\mathrm{B} \neq \phi
$$

Let $b \in B$ and $B a \in A_{1}$ then $b \in B_{a}$ so $M(b, a, t) \geq 1-(1-M(a, T a, t))=M(a, T a, t)$. If $\mathrm{a}=\mathrm{b}$ then $\mathrm{B}_{\mathrm{a}}=\mathrm{B}_{\mathrm{b}}$. Assume that $\mathrm{a} \neq \mathrm{b}$, for any $\mathrm{x} \in \mathrm{B}_{\mathrm{b}}$

$$
M(x, a, t) \geq \min \{M(x, b, t), M(b, a, t)\} \geq M(a, T a, t)
$$
and

$$
\begin{aligned}
\mathrm{M}(\mathrm{x}, \mathrm{b}, \mathrm{t}) & \geq 1-(1-\mathrm{M}(\mathrm{b}, \mathrm{Tb}, \mathrm{t}) \\
= & \mathrm{M}(\mathrm{b}, \mathrm{Tb}, \mathrm{t}) \\
& \geq \min \{\mathrm{M}(\mathrm{b}, \mathrm{a}, \mathrm{t}), \mathrm{M}(\mathrm{a}, \mathrm{Ta}, \mathrm{t}), \mathrm{M}(\mathrm{Ta}, \mathrm{Tb}, \mathrm{t})\} \\
= & \min \{\mathrm{M}(\mathrm{a}, \mathrm{Ta}, \mathrm{t}), \mathrm{M}(\mathrm{Ta}, \mathrm{Tb}, \mathrm{t})\}=\mathrm{M}(\mathrm{a}, \mathrm{Ta}, \mathrm{t})
\end{aligned}
$$

So $\mathrm{B}_{\mathrm{b}} \subseteq \mathrm{B}_{\mathrm{a}}$ for any $\mathrm{B}_{\mathrm{a}} \in \mathrm{A}_{1}$. Thus $\mathrm{B}_{\mathrm{b}}$ is the upper bound for the family $\mathrm{A}_{1}$. By Zorn's lemma there is a maximal element in $\mathrm{A}_{1}$, say $\mathrm{B}_{\mathrm{z}}$.

For any $b \in B_{z}$

$M(b, T b, t) \geq \min \{M(b, z, t), M(z, T z, t), M(T z, T b, t)\}$

$$
\geq \min \{\mathrm{M}(\mathrm{b}, \mathrm{z}, \mathrm{t}), \mathrm{M}(\mathrm{z}, \mathrm{Tz}, \mathrm{t}), \mathrm{M}(\mathrm{z}, \mathrm{b}, \mathrm{t})\}=\mathrm{M}(\mathrm{z}, \mathrm{Tz}, \mathrm{t})
$$

$\mathrm{B}_{\mathrm{b}} \cap \mathrm{B}_{\mathrm{z}}$ is nonempty (contains $\mathrm{b}$ ) so by above Proposition,

$$
\mathrm{B}_{\mathrm{b}} \subseteq \mathrm{B}_{\mathrm{z}} \text {. }
$$

Since $\mathrm{Tb} \in \mathrm{B}_{\mathrm{b}}$ we just prove that $\mathrm{T}: \mathrm{Bz} \rightarrow \mathrm{Bz}$.

For $\mathrm{z}=\mathrm{Tz} \mathrm{f}(\mathrm{x})=0$ so theorem is proved.

For $\mathrm{z} \neq \mathrm{Tz}$ we are going to prove that $\mathrm{f}(\mathrm{b})=\mathrm{f}(\mathrm{z})$ for every $\mathrm{b} \in \mathrm{Bz}$.

We know that $M(b, T b, t) \geq M(z, T z, t)$ for any $b \in B z$. Let us suppose that for some $b \in B_{z}$

$$
\begin{aligned}
& M(b, T b, t)>M(z, T z, t) \\
& M(b, z, t) \geq M(z, T z, t)
\end{aligned}
$$

then

$$
\begin{aligned}
\mathrm{M}(\mathrm{z}, \mathrm{Tz}, \mathrm{t}) & \geq \min \{\mathrm{M}(\mathrm{z}, \mathrm{b}, \mathrm{t}), \mathrm{M}(\mathrm{b}, \mathrm{Tz}, \mathrm{t})\} \\
& \geq \min \{\mathrm{M}(\mathrm{z}, \mathrm{b}, \mathrm{t}), \mathrm{M}(\mathrm{b}, \mathrm{Tb}, \mathrm{t}), \mathrm{M}(\mathrm{Tb}, \mathrm{Tz}, \mathrm{t})\} \\
& \geq \min \{\mathrm{M}(\mathrm{z}, \mathrm{b}, \mathrm{t}), \mathrm{M}(\mathrm{b}, \mathrm{Tb}, \mathrm{t}), \mathrm{M}(\mathrm{b}, \mathrm{z}, \mathrm{t})\} \\
& =\min \{\mathrm{M}(\mathrm{z}, \mathrm{b}, \mathrm{t}), \mathrm{M}(\mathrm{b}, \mathrm{Tb}, \mathrm{t})\} \\
& =\mathrm{M}(\mathrm{z}, \mathrm{b}, \mathrm{t})
\end{aligned}
$$


we obtain that $M(z, T z, t)=M(b, z, t)$.

But

$$
\mathrm{M}(\mathrm{b}, \mathrm{z}, \mathrm{t})=\mathrm{M}(\mathrm{z}, \mathrm{Tz}, \mathrm{t}) \leq \mathrm{M}(\mathrm{b}, \mathrm{Tb}, \mathrm{t})
$$

implies that $\mathrm{z} \in \mathrm{Bz}$ but $\mathrm{z} \notin \mathrm{B}_{\mathrm{b}}$ and hence

$$
\mathrm{B}_{\mathrm{b}} \underset{\neq}{\subset} \mathrm{B}_{\mathrm{z}}
$$

which contradicts the maximality of Bz.

Thus we proved that $\mathrm{f}$ is m.l.c. on $\mathrm{B}=\mathrm{B}_{\mathrm{z}}$.

Theorem 2.5: Let $(X, M, *, \diamond)$ be spherically complete non-Archimedean fuzzy metric space. If $f$ and $T$ are two self maps satisfying

$T(X) \subseteq f(X)$

and

$M(T x, T y, t) \geq \min \{M(f x, f y, t), M(f x, T x, t), M(f y, T y, t)\}$

then there exists $z \in X$ such that $f z=T z$.

Further if $f$ and $T$ are coincidentally commuting at $z$ then $z$ is the unique common fixed point off and $T$.

Proof: Let $B_{a}=(f a, 1-M(f a, T a, t))$ denote the closed sphere centered at fa with the radius $1-\mathrm{M}(\mathrm{fa}, \mathrm{Ta}, \mathrm{t})$ and let $\mathrm{A}$ be the collection of these spheres for all $\mathrm{a} \in \mathrm{X}$. Then the relation $\mathrm{B}_{\mathrm{a}} \leq \mathrm{B}_{\mathrm{b}}$ iff $\mathrm{B}_{\mathrm{b}} \subseteq \mathrm{B}_{\mathrm{a}}$ is a partial order on $\mathrm{A}$. Let $\mathrm{A}_{1}$ be a totally ordered sub family of A.

Since $(\mathrm{X}, \mathrm{M}, *, \diamond)$ is spherically complete, we have $\underset{B_{a} \in A_{1}}{\cap} \mathrm{B}_{\mathrm{a}}=\mathrm{B} \neq \phi$.

Let $\mathrm{fb} \in \mathrm{B}$ and $\mathrm{B}_{\mathrm{a}} \in \mathrm{A}_{1}$. Then $\mathrm{fb} \in \mathrm{B}_{\mathrm{a}}$. Hence

$$
M(f b, f a, t) \geq M(f a, T a, t)
$$

If $\mathrm{a}=\mathrm{b}$ then $\mathrm{B}_{\mathrm{a}}=\mathrm{B}_{\mathrm{b}}$. Assume that $\mathrm{a} \neq \mathrm{b}$.

Let $\mathrm{x} \in \mathrm{B}_{\mathrm{b}}$. Then

$\operatorname{from}(2.5)$

$$
\begin{aligned}
M(x, f b, t) & \geq M(f b, T b, t) \\
\geq \min & \{M(f b, f a, t), M(f a, T a, t), M(T a, T b, t)\} \\
= & \min \{M(f a, T a, t), M(T a, T b, t)\} \quad \text { from(i) } \\
& >\min \{M(f a, f b, t), M(f a, T a, t), M(f b, T b, t)\}
\end{aligned}
$$

$$
\begin{aligned}
& =\mathrm{M}(\mathrm{fa}, \mathrm{Ta}, \mathrm{t}) \\
& =\mathrm{N}(\mathrm{fa}, \mathrm{Ta}, \mathrm{t})
\end{aligned}
$$

Now, $M(x, f a, t) \geq \min \{M(x, f b, t), M(f b, f a, t)\} \geq M(f a, T a, t) \quad$ from(i) and (ii). 
Thus $\mathrm{x} \in \mathrm{B}_{\mathrm{a}}$. Hence $\mathrm{B}_{\mathrm{b}} \subseteq \mathrm{B}_{\mathrm{a}}$ for any $\mathrm{B}_{\mathrm{a}} \in \mathrm{A}_{1}$. Thus $\mathrm{B}_{\mathrm{b}}$ is an upper bound in $\mathrm{A}$ for the family $\mathrm{A}_{1}$ and hence by Zorn's Lemma, A has a maximal element, say $\mathrm{B}_{\mathrm{z}}, \mathrm{z} \in$ $\mathrm{X}$.

Suppose $\mathrm{fz} \neq \mathrm{Tz}$. Since $\mathrm{Tz} \in \mathrm{T}(X) \subseteq \mathrm{f}(X)$, there exists $\mathrm{w} \in X$ such that $\mathrm{Tz}=\mathrm{fw}$. Clearly $z \neq w$. Now from (2.5) we have

$$
\begin{aligned}
& \mathrm{M}(\mathrm{fw}, \mathrm{Tw}, \mathrm{t})=\mathrm{M}(\mathrm{Tz}, \mathrm{Tw}, \mathrm{t}) \\
& \geq \min \{M(f z, f w, t), M(f z, T z, t), M(f w, T w, t)\}
\end{aligned}
$$

$\operatorname{from}(2.5)$

$$
=\mathrm{M}(\mathrm{fz}, \mathrm{fw}, \mathrm{t})
$$

Thus $\mathrm{fz} \notin \mathrm{B}_{\mathrm{w}}$. Hence $\mathrm{B}_{\mathrm{z}} \not \subset \mathrm{B}_{\mathrm{w}}$. It is a contradiction to the maximality of $\mathrm{B}_{\mathrm{z}}$. Hence $\mathrm{fz}=\mathrm{Tz}$.

Further assume that $\mathrm{f}$ and $\mathrm{T}$ are coincidentally commuting at $\mathrm{z}$.

Then $\mathrm{f}^{2} \mathrm{z}=\mathrm{f}(\mathrm{fz})=\mathrm{fTz}=\mathrm{Tfz}=\mathrm{T}(\mathrm{Tz})=\mathrm{T}^{2} \mathrm{z}$.

Suppose $f z \neq z$. Now from (2.2), we have

$$
\begin{aligned}
M(T f z, T z, t) & \geq \min \left\{M\left(f^{2} z, f z, t\right), M\left(f^{z} z, T f z, t\right), M(f z, T z, t)\right\} \\
= & M(T f z, T z, t) .
\end{aligned}
$$

Hence $f z=z$. Thus $z=f z=T z$. Uniqueness of common fixed point of $f$ and $T$ follows easily from(2.5).

Theorem 2.6: Let $(\mathrm{X}, \mathrm{M}, *, \diamond)$ be spherically complete non- Archimedean fuzzy metric space. Let $\mathrm{f}: \mathrm{X} \rightarrow \mathrm{X}$ and $\mathrm{T}: \mathrm{X} \rightarrow \mathrm{C}(\mathrm{X})$ be satisfying

$\mathrm{T}(\mathrm{X}) \subseteq \mathrm{f}(\mathrm{X}) \quad \forall \mathrm{x} \in \mathrm{X}$,

$\mathrm{H}(\mathrm{Tx}, \mathrm{Ty}, \mathrm{t}) \geq \min \{\mathrm{M}(\mathrm{fx}, \mathrm{fy}, \mathrm{t}), \mathrm{M}(\mathrm{fx}, \mathrm{Tx}, \mathrm{t}), \mathrm{M}(\mathrm{fy}, \mathrm{Ty}, \mathrm{t})\} \quad \forall \mathrm{x}, \mathrm{y} \in \mathrm{X}, \mathrm{x} \neq \mathrm{y}$

then there exists $\mathrm{z} \in \mathrm{X}$ such that $\mathrm{fz} \in \mathrm{Tz}$.

Further assume that

$\mathrm{M}(\mathrm{fx}, \mathrm{fu}, \mathrm{t}) \geq \mathrm{H}(\mathrm{Tfy}, \mathrm{Tu}, \mathrm{t}) \quad \forall \mathrm{x}, \mathrm{y}, \mathrm{u} \in \mathrm{X}, \mathrm{fx} \in \mathrm{Ty}$

and

$\mathrm{f}$ and $\mathrm{T}$ are coincidentally commuting at $\mathrm{z}$.

Then $\mathrm{fz}$ is the unique common fixed point of $\mathrm{f}$ and $\mathrm{T}$.

Proof: Let $B_{a}=(f a, 1-M(f a, T a, t))$ denote the closed sphere centered at fa with the radius $1-\mathrm{M}(\mathrm{fa}, \mathrm{Ta}, \mathrm{t})$ and let $\mathrm{A}$ be the collection of these spheres for all $\mathrm{a} \in \mathrm{X}$. Then the relation $\mathrm{B}_{\mathrm{a}} \leq \mathrm{B}_{\mathrm{b}}$ iff $\mathrm{B}_{\mathrm{b}} \subseteq \mathrm{B}_{\mathrm{a}}$ is a partial order on $\mathrm{A}$. Let $\mathrm{A}_{1}$ be a totally ordered sub family of A.

Since $(\mathrm{X}, \mathrm{M}, *, \diamond)$ is spherically complete, we have $\underset{B_{a} \in A_{1}}{\cap} \mathrm{B}_{\mathrm{a}}=\mathrm{B} \neq \phi$. 
Let $\mathrm{fb} \in \mathrm{B}$ and $\mathrm{B}_{\mathrm{a}} \in \mathrm{A}_{1}$. Then $\mathrm{fb} \in \mathrm{B}_{\mathrm{a}}$. Hence

$$
M(f b, f a, t) \geq M(f a, T a, t)
$$

If $\mathrm{a}=\mathrm{b}$ then $\mathrm{B}_{\mathrm{a}}=\mathrm{B}_{\mathrm{b}}$. Assume that $\mathrm{a} \neq \mathrm{b}$.

Let $\mathrm{x} \in \mathrm{B}_{\mathrm{b}}$. Then

$$
M(x, f b, t) \geq M(f b, T b, t) .
$$

Since Ta is compact, there exists $\mathrm{u} \in \mathrm{Ta}$ such that

Consider

$$
M(f a, u, t)=M(f a, T a, t)
$$

Thus

$$
\begin{aligned}
\mathrm{M}(\mathrm{fb}, \mathrm{Tb}, \mathrm{t}) & =\inf _{c \in T b} \mathrm{M}(\mathrm{fb}, \mathrm{c}, \mathrm{t}) \\
& \geq \min \left\{\mathrm{M}(\mathrm{fb}, \mathrm{fa}, \mathrm{t}), \mathrm{M}(\mathrm{fa}, \mathrm{u}, \mathrm{t}), \inf _{c \in T b} M(u, c, t)\right\} \\
\geq \min \{\mathrm{M}(\mathrm{fb}, \mathrm{Ta}, \mathrm{t}), \mathrm{M}(\mathrm{Ta}, \mathrm{Tb}, \mathrm{t})\} & \text { from (i) and (ii) } \\
>\min \{\mathrm{M}(\mathrm{fb}, \mathrm{Ta}, \mathrm{t}), \mathrm{M}(\mathrm{Ta}, \mathrm{fb}, \mathrm{t})\} & \text { from (i) and (2.7) }
\end{aligned}
$$

Now,

$$
M(f b, T b, t)>M(f a, T a, t)
$$

$$
\begin{aligned}
M(x, f a, t) & \geq \min \{M(x, f a, t), M(f b, f a, t)\} \\
& \geq M(f a, T a, t) \quad \text { from (i) and (iii). }
\end{aligned}
$$

Thus $\mathrm{x} \in \mathrm{B}_{\mathrm{a}}$. Hence $\mathrm{B}_{\mathrm{b}} \subseteq \mathrm{B}_{\mathrm{a}}$ for any $\mathrm{B}_{\mathrm{a}} \in \mathrm{A}_{1}$. Thus $\mathrm{B}_{\mathrm{b}}$ is an upper bound in $\mathrm{A}$ for the family $\mathrm{A}_{1}$ and hence by Zorn's Lemma, $\mathrm{A}$ has a maximal element, say

$\mathrm{B}_{\mathrm{z}}, \mathrm{z} \in \mathrm{X}$.

Suppose $\mathrm{fz} \notin \mathrm{Tz}$. Since $\mathrm{Tz}$ is compact, there exists $\mathrm{k} \in \mathrm{Tz}$ such that

$M(f z, T z, t)=M(f z, k, t)$. From (2.6), there exists $w \in X$ such that $k=f w$. Thus

$$
M(f z, T z, t)=M(f z, f w, t)
$$

Clearly $\mathrm{z} \neq \mathrm{w}$. Now,

$$
\mathrm{M}(\mathrm{fw}, \mathrm{Tw}, \mathrm{t}) \geq \mathrm{H}(\mathrm{Tz}, \mathrm{Tw}, \mathrm{t})
$$

$$
\begin{aligned}
& \geq \min \{\mathrm{M}(\mathrm{fz}, \mathrm{fw}, \mathrm{t}), \mathrm{M}(\mathrm{fz}, \mathrm{Tz}, \mathrm{t}), \mathrm{M}(\mathrm{fw}, \mathrm{Tw}, \mathrm{t})\} \\
& =\mathrm{M}(\mathrm{fz}, \mathrm{fw}, \mathrm{t}) \\
& \text { from (iv) }
\end{aligned}
$$

Hence, $f z \notin \mathrm{B}_{\mathrm{w}}$. Thus $\mathrm{B}_{\mathrm{z}} \not \subset \mathrm{B}_{\mathrm{w}}$. It is a contradiction to the maximality of $\mathrm{B}_{\mathrm{z}}$.

Hence $f z \in T z$. Further assume (2.8) and (2.9). Write $f z=p$. Then, $p \in T z$. From (2.8), $M(p, f p, t)=M(f z, f p, t) \geq H(T f z, T p, t)=H(T p, T p, t)=0$. This implies that $\mathrm{fp}=\mathrm{p}$.

From (2.9), $p=f p \in f T z \subseteq T f z=T p$. Thus $f z=p$ is a common fixed point of $f$ and $\mathrm{T}$.

Suppose $\mathrm{q} \in \mathrm{X}, \mathrm{q} \neq \mathrm{p}$ is such that $\mathrm{q}=\mathrm{fq} \in \mathrm{Tq}$. From (2.7) and (2.8) we have $M(p, q, t)=M(f p, f q, t) \geq H(T f p, T q, t)=H(T p, T q, t)$

$$
\begin{aligned}
& >\min \{\mathrm{M}(\mathrm{fp}, \mathrm{fq}, \mathrm{t}), \mathrm{M}(\mathrm{fp}, \mathrm{Tp}, \mathrm{t}), \mathrm{M}(\mathrm{fq}, \mathrm{Tq}, \mathrm{t})\} \\
& =\mathrm{M}(\mathrm{p}, \mathrm{q}, \mathrm{t}) .
\end{aligned}
$$

This implies that $\mathrm{p}=\mathrm{q}$. Thus $\mathrm{p}=\mathrm{fz}$ is the unique common fixed point of $\mathrm{f}$ and $\mathrm{T}$. 


\section{References}

[1] A. George and P. Veeramani, Some results in fuzzy metric space, Fuzzy sets and system, 64(1994),395-399.

[2] D, Mihet, A Banach contraction theorem in fuzzy metric spaces, Fuzzy Sets and System 144(2004),431-439.

[3] D, Mihet, fuzzy $\psi$-contractive mappings in non- Archimedean fuzzy metric spaces, Fuzzy sets and system 159(2008) 739-744.

[4] E. Pap, O. Hadzic and R. Mesiar, A fixed point theorem in probabilistic metric spaces and an application, J. Math. Anal. Appl. 202(1996), 433-449.

[5] J. Goguen, L-fuzzy sets, J. Math. Anal. Appl. 18(1967), 145-174.

[6] G. Jungck.and B.E. Rhoades, Fixed point for set valued functions without continuity, Indian J. Pure Appl. Math., 29(1998),227-238.

[7] K.P.R.Rao \& G.N.V.Kishore, Common fixed point theorems in Ultra Metric Spaces, Journal of Mathematics, 40(2008), 31-35.

[8] K.P.R.Rao, G.N.V.Kishore and T. Ranga Rao, Some Coincidence Point Theorems in Ultra Metric Spaces, Int. Journal of Math. Analysis, 1(2007), 897-902.

[9] Ljilijana Gajic, On Ultrametrc Space, Novi Sad J. Math.,31 (2)(2001),69-71.

[10] Ljilijana Gajic, Metric Locally Constant Function on some subset of Ultrametrc Space, Novi Sad J. Math., 35(1)(2005),123-125.

[11] L.A. Zadeh , Fuzzy sets, inform. And control 8(1965),338-353.

[12] M.A. Erceg, J.Math. Anal. Appl., 69(1979),205-230.

[13] M.Vajaitu and A. Zaharescu, Group of isometries on ultrametric spaces, Bull.Math. Soc. Sci. Math. Roumanie 44(92)(2001),183-191.

[14] O.Kleva and O. Seikkala, On fuzzy metric spaces, Fuzzy sets and system,12(1984),215.

[15] S. S.Chang , Y. J. Cho, B. S. Lee, J.S. Jung and S. M. Kang, Coincidence point and minimization theorems in fuzzy metric spaces Fuzzy sets and system 88(1997), 119-128.

[16] V.Popa, A General Fixed Point Theorem for Mappings in Ultra Metric Spaces, Universitatea Din Bacau Studii Si Cercetari Stiintifice, 18(2008),249-254.

[17] V. Gregori and A. Sapena, On fixed point theorem in fuzzy metric spaces, Fuzzy Sets and System125(2002),245-252.

[18] Y. J. Cho, H.K. Pathak, S. M. Kang and J.S. Jung, Common fixed points of compatible maps of type ( $\beta$ ) in fuzzy metric spaces, Fuzzy sets and system 93(1998), 99-111.

[19] Y.J.Cho, H. K. Pathak, S.M. Kang and J.S.Jung, Common fixed points of compatible maps of type $(\beta)$ in fuzzy metric spaces, Fuzzy sets and Systems 93(1998),99-111.

[20] Z.K. Deng, Fuzzy Pseudo metric spaces, J. Math. Anal. Appl , 86(1982),7495. 